\title{
The Effect of Burnout, Stress, Depression, and Anxiety on the General Efficacy of Health Service Provision Among Chinese Nurses During Coronavirus disease 2019 outbreak: A Single-Center Survey.
}

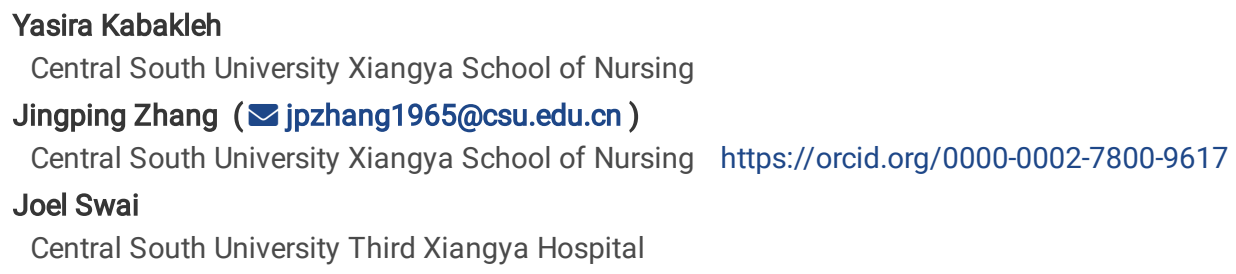




\section{Abstract}

Background: In-person caring for coronavirus disease patients amid the outbreak and shortage of medical supplies create burnout and fear of getting infected among healthcare workers. These deem questioning service provision's efficacy by healthcare workers. This study aims to explore the effect of burnout, stress, depression, and anxiety on the efficacy of health service provision among nurses during the Coronavirus disease outbreak in China, by multiple linear regression

Methods: Our Cross-sectional study utilized three Chinese versions of validated questionnaires; Maslach Burnout Inventory, The General Self-Efficacy Scale, and Depression Anxiety Stress Scales to assess burnout, efficacy, and anxiety among Chinese nurses caring for Coronavirus disease patients during the outbreak. We performed multiple linear regression with burnout, depression, anxiety, and stress scores as independent variables versus general self-efficacy scores as the dependent variable. We used SPSS at a $95 \%$ level of significance in the data analysis, and the STROBE tool in the write-up.

Results: There was a total of 408 study participants. The majority showed high levels of depersonalization, emotional exhaustion, low levels of personal achievements, and extremely high levels of depression, anxiety, and stress. The general self-efficacy was below the international average. Emotional exhaustion and stress demonstrated a small negative correlation with general self-efficacy. The effect of anxiety and depression on the general self-efficacy was not statistically significant.

Conclusions: Coronavirus disease outbreak in China, overwhelmed healthcare facilities creating burnout, anxiety, stress, and depression among nurses working in the hard-hit areas. These may explain an observed lower than average general self-efficacy. However, only stress and emotional exhaustion were associated with reduced general self-efficacy among nurses.

\section{Background}

Believed to have started from a fish market in a twelve million city of Wuhan in China, coronavirus disease (COVID-19) grew from a localized epidemic to a global pandemic in about three months since its initial outbreak in late 2019. It had infected more than 450,000 people worldwide, as of 25th March $2020(1,2)$. The viral strain was new to the human host. The virus name evolved from unofficial Wuhan coronavirus, 2019-nCoV to the severe acute respiratory syndrome coronavirus 2 (SARS-CoV-2) $(1,3,4)$. The COVID-19 affects all age groups at an estimated mortality rate of $3.4 \%$; however, older and comorbid people are more vulnerable to severe disease. (5).

With 2-14 days estimated incubation period (6), COVID-19 has negatively impacted governments' budgets, production, and the world's supply chain, threatening to plummet the world economy (7). With no licensed vaccine or definitive cure, governments are taking drastic measures to increase public awareness on prevention through social-distancing, as well as strengthening healthcare systems in terms of screening, testing, and management of confirmed patients (8). However, it is evident that governments with weaker healthcare systems could face more enormous challenges as compared to governments with more reliable healthcare systems (9).

China being the epicenter of the outbreak, reported the highest proportion of cases worldwide with a new number of cases reaching 15,000 cases per day during the peak of the disease in mid-February 2020. The situation overwhelmed health care facilities (10). The flooding of patients attending healthcare facilities not only led to fatigue and burnout among healthcare workers but also increased the risk of infection among healthcare workers. As of March 4th, more than 3,300 healthcare workers had contracted the virus in China, and at least 18 had died (10). The situation also caused an increased risk of nosocomial transmission among patients.

Despite these challenges, healthcare facilities across the globe developed a variety of mitigation measures to ensure the quality of service was not affected. Amid the outbreak, the Chinese government saw the need to mobilize health workers countrywide (11). This effort served to ease the burden that healthcare facilities faced in the hardest-hit areas, particularly Wuhan. In the US and Europe, on the other hand, several healthcare facilities employed the use of telemedical innovations in caring for COVID-19 patients. This aimed at reducing the risk of nosocomial infections resulting from in-person patients care. The method had proven to be conducive for quarantined individuals and protective to patients and health care workers as compared to in-person care (12). This being recently utilized in managing COVID-19 patients, it was not used in China amid the peak of the outbreak.

From the healthcare workers' perspective, in-person caring for COVID-19 patients during the outbreak creates burnout due to a large number of inflowing patients, as well as emotional disturbances, including fear of getting infected at work and depression. The situation led to the concern of the efficacy of health services provided by exhausted and anxious healthcare workers. The aim of this study was, therefore, to explore the effect of burnout, stress, depression, and anxiety on the efficacy of health service provision among drafted nurses returning from Wuhan.

\section{Methods}

\section{Design}

Our study was a cross-sectional study involving 408 (100\% response rate) drafted nurses, returning to our institution from Wuhan. These nurses were directly involved in the treatment of COVID-19 patients during the outbreak in Wuhan. We maintained communications with participants through a 
social-network mobile application, WeChat (13), that all drafted nurses from our institution shared.

\section{Data collection}

Three validated questionnaires, the Maslach Burnout Inventory (MBI), the General Self-Efficacy Scale (GSES), and Depression Anxiety Stress Scales (DASS), were utilized for data collection. Socio-demographic characteristics, including age, sex, marital status, and education level, were collected. We collected data for a week, from March 16, 2020. We "electronically," prepared, shared, and received all dully-filled questionnaires from participants to reduce the risk of contamination by "paper-based" questionnaires as fomites.

\section{Maslach Burnout Inventory (MBI)}

$\mathrm{MBI}$ is a validated tool for measuring burnout among workers (14). In this study, a validated Chinese version of the MBI tool for human service survey was utilized (15). The tool contains three subscales; depersonalization ( 6 items), emotional exhaustion (9 items), and reduction in personal accomplishment (10 items), each of which corresponds with a normal score range of 6-9, 19-26, and 34-39, respectively. Scores below 6 and above 9 on the depersonalization subscale indicate higher and lower levels of burnout in terms of depersonalization, respectively. Scores below 19 and above 26 on the emotional exhaustion subscale indicate lower and higher levels of burnout in terms of emotional exhaustion, respectively. Scores below 34 and above 39 on the personal achievement subscale indicate lower and higher levels of burnout in terms of reduction in personal achievement, respectively. The internal consistency indices (Cronbach's a) for each of the three parts are $0.842,0.912$, and 0.793 for depersonalization, emotional exhaustion, and personal accomplishment, respectively (16). We sought permission to use the tool from Mind Garden Inc. available at https://www.mindgarden.com/

\section{The General Self-Efficacy Scale (GSES)}

GSES is a validated scale to measure the feeling of self-efficacy in an individual's deed (17). In this study, we used the validated Chinese version of the tool (18) to measure nurses' self-efficacy in managing patients amid the COVID-19 outbreak. The scale consists of ten Likert-scored questions summing to a minimum of 10 and a maximum of 40 . A higher score indicates higher self-efficacy. The international average score is 29.55 (17). The internal consistency (Cronbach's alpha) for the scale is 0.92 (18). Since this scale is a public domain, no permission to use was needed.

\section{Depression Anxiety Stress Scales (DASS)-21}

DASS-21 is a validated scale used to measure three negative emotional states of depression, anxiety, and stress. In this study, the short version of the validated simplified Chinese scale was used (19). The scale consists of 21 Likert-scored questions summing to the minimum and maximum of zero and 21, respectively, for each of the three scales. The higher score indicates a higher level of depression, anxiety, or stress.

Depression score can be Normal (0-4), Mild (5-6), Moderate (7-10) Severe (11-13), or Extremely severe ( $\geq 14)$. Anxiety score can be Normal (0-3), Mild (4-5), Moderate (6-7), Severe (8-9), Extremely severe ( $\geq 10)$. Stress score can be Normal (0-7), Mild (8-9), Moderate (10-12), Severe (13-16), Extremely severe ( $\geq 17)$.

The internal consistencies (Cronbach's alpha) for the scale are $0.83,0.80$, and 0.82 for the depression, anxiety, and stress scales, respectively. The Cronbach's alpha for the overall DASS-21 is 0.92. Since this scale is a public domain, no permission to use is needed (20).

\section{Calculation of sample size}

We calculated the sample size by using the following formula (Daniel, 1999); $n=(z)^{2} p(1-p) / d^{2}$. Where, $n=$ the estimated sample size, $z=$ the standard normal deviation at $95 \%$ confidence level set as $1.96, p=$ the estimated proportion of problem $25 \%(21), q=1-p$ and $d=$ the precision error set as $5 \%$. Substituting the values into the formula; $\mathrm{n}=\left[1.96^{2} \times 0.25(1-0.75)\right] /(0.05)^{2}=288.12$. Therefore, a minimum of 288 nurses needed to be included in the sample.

Bias

We assessed detection, information, and self-selection biases. To minimize reporting biases, a tool, Strengthening the Reporting of Observational Studies in Epidemiology (Supplementary File 1) customized for the cross-sectional study was used in the write-up.

\section{Ethical consideration}

We sought written consent from the participants. We sought the approval to conduct this study from the Institution's review board (IRB) of behavioral and nursing research in School of Nursing of Central South University (CSU). The study's approval number was 2018035.

\section{Analysis}

We performed multiple linear regression to assess the effect of burnout and anxiety towards general self-efficacy. All scores were continuous variables. The three burnout sub-scales from MBI were analyzed separately as depersonalization, emotional exhaustion, and personal achievement. DASS-21 questionnaire provided depression, stress, and anxiety scores. The GSES questionnaire provided general self-efficacy scores. DASS-21 and MBI-HSS scores were our independent variables, while GSES scores served as dependent variables. We used the computer software, SPSS for analysis at a $95 \%$ level of significance. We performed forward-selection and backward-elimination multiple linear regression as additional analyses. A correlation coefficient of more than 0.7 defined the presence of multicollinearity between predictor variables.

Page $3 / 10$ 


\section{Results}

A total of 408 nurses (Mean age: $36.67 \pm 11.21$ ) returned from Wuhan, where they were directly involved in treating COVID-19 patients. All drafted nurses (100\%) participated in our study. Table 1 illustrates the participants' demographic characteristics.

Table 1

Demographic characteristics

\begin{tabular}{|c|c|c|}
\hline Demographic data & Demographic data sub-groups & Frequency (Percentage) \\
\hline \multirow[t]{4}{*}{ age } & $20-29$ & $107(24.4)$ \\
\hline & $30-39$ & $112(25.6)$ \\
\hline & $40-49$ & $91(20.8)$ \\
\hline & $50-59$ & $98(22.4)$ \\
\hline \multirow[t]{2}{*}{ Gender } & Male & $0(0)$ \\
\hline & Female & $408(100)$ \\
\hline \multirow[t]{4}{*}{ Level of education } & Technical Secondary School or college & $192(47.1)$ \\
\hline & Bachelor's degree & $191(46.8)$ \\
\hline & Master's degree & $14(3.4)$ \\
\hline & $\mathrm{PhD}$ & $11(2.7)$ \\
\hline \multirow[t]{4}{*}{ Marriage } & Married & $108(26.4)$ \\
\hline & Unmarried & $279(68.4)$ \\
\hline & Divorced & $11(2.7)$ \\
\hline & Widowed & $10(2.5)$ \\
\hline
\end{tabular}

\section{Descriptive statistics}

Regarding burnout, the majority of participants demonstrated high levels of depersonalization (73.1\%), emotional exhaustion (57.8\%), and low levels of personal achievements (59.1\%), Table 2 .

The majority of participants had extremely high levels of depression (88.48\%), anxiety (100\%), and stress (99.76\%). Regarding self-efficacy, all participants (100\%) had levels below the international average.

The mean depression score was $16.93 \pm 2.78$, indicating extremely severe depression. The mean anxiety score was $18.98 \pm 0.68$, indicating extremely severe anxiety. The mean stress score was $15.02 \pm 2.20$, indicating a severe level of stress, and the mean general self-efficacy score was $14.28 \pm 2.12$ indicating a below-average general-self-efficacy.

Table 2

Frequency table for burnout levels among participants

\begin{tabular}{|llll|}
\hline Level/Disorder & $\begin{array}{l}\text { Depersonalization frequency } \\
\text { (percentage) }\end{array}$ & $\begin{array}{l}\text { Emotional Exhaustion frequency } \\
\text { (percentage) }\end{array}$ & $\begin{array}{l}\text { Personal Achievement frequency } \\
\text { (percentage) }\end{array}$ \\
\hline Low & $34(7.8)$ & $84(19.2)$ & $259(59.1)$ \\
\hline Normal & $54(12.3)$ & $71(16.2)$ & $48(11.0)$ \\
\hline High & $320(73.1)$ & $253(57.8)$ & $101(23.1)$ \\
\hline Mean scores & Mean: 15.72;Standard deviation: 7.28 & Mean 30.51; Standard deviation: 13.72 & Mean 29.65: Standard deviation: 14.88 \\
\hline
\end{tabular}

\section{Regression analysis}

Table 3 illustrates a table of coefficients from the multiple linear regression model. The independent variables did not show multicollinearity. There was a linear relationship between the independent variable and dependent variables, Figs. 1\&2. Cook's distance ranged from $0.00-0.038$. This model explained $4.9 \%$ of the variance in the dependent variable $\left(R^{2}=0\right.$, p-Value 0.002$)$. 
Table 3

Table of coefficients

\begin{tabular}{|lllllcr}
\hline Model & $\begin{array}{l}\text { Unstandardized } \\
\text { Coefficients }\end{array}$ & $\begin{array}{l}\text { Standardized } \\
\text { Coefficients }\end{array}$ & t-test & p-Values & \multicolumn{2}{c}{ Correlations } \\
\cline { 2 - 5 } & Beta $\quad$ Standard error & Beta & Zero-order & Partial \\
\hline
\end{tabular}

\begin{tabular}{|c|c|c|c|c|c|c|c|c|}
\hline (Constant) & 18.006 & 3.084 & & 5.839 & 0.000 & & & \\
\hline $\begin{array}{l}\text { Personal } \\
\text { Achievement }\end{array}$ & 0.004 & 0.007 & 0.027 & 0.557 & 0.578 & 0.030 & 0.028 & 0.027 \\
\hline $\begin{array}{l}\text { Emotional } \\
\text { Exhaustion }\end{array}$ & -0.016 & 0.008 & -0.105 & -2.132 & 0.034 & -0.102 & -0.106 & -0.104 \\
\hline Depersonalization & 0.025 & 0.014 & 0.088 & 1.786 & 0.075 & 0.084 & 0.089 & 0.087 \\
\hline Depression & -0.031 & 0.037 & -0.041 & -0.827 & 0.409 & -0.040 & -0.041 & -0.040 \\
\hline Anxiety & -0.279 & 0.154 & -0.090 & -1.812 & 0.071 & -0.087 & -0.090 & -0.088 \\
\hline Stress & -0.138 & 0.047 & 0.144 & 2.935 & 0.004 & 0.147 & 0.145 & 0.143 \\
\hline \multicolumn{9}{|c|}{ Dependent Variable: Self-efficacy } \\
\hline \multicolumn{9}{|c|}{ Bolded are statistically significant $p$-Values $(<0.05)$} \\
\hline
\end{tabular}

Emotional exhaustion, anxiety, stress, and depression demonstrated small negative correlations with general self-efficacy. From the regression, every one-unit increase in the emotional exhaustion scale was associated with a 0.016 reduction in the general self-efficacy ( $p$-Value $=0.034$ ). Moreover, for every one-unit increase in the stress scale was associated with a 0.138 decrease in the general self-efficacy ( $p$-Value $=0.004)$. The effect of anxiety and depression to the general self-efficacy did not show statistical significance.

Personal achievement demonstrated a small positive correlation with general self-efficacy. From the regression, a one-unit increase in the level of personal achievement was associated with a 0.004 increase in the general self-efficacy. However, this result did not reach statistical significance (pValue $=0.578)$

Counterintuitively, depersonalization showed a small positive correlation with general self-efficacy. From the regression, a one-unit increase in the level of depersonalization was associated with a 0.025 increase in the general self-efficacy. However, this unexpected finding did not reach statistical significance $(p-$ Value $=0.075)$.

\section{Additional analysis}

We additionally conducted a forward-selection and backward-eliminations multiple linear regressions. A forward selection method systematically identified only variables with less than 0.05 level of significance, Table 4, while backward elimination methods systematically eliminated all variables with more than 0.10 level of significance, Table 5 .

Table 4

Forward-selection multiple linear regression.

\begin{tabular}{|c|c|c|c|c|c|c|c|c|}
\hline \multirow[t]{2}{*}{ Model } & \multicolumn{2}{|c|}{ Unstandardized Coefficients } & \multirow{2}{*}{$\begin{array}{l}\text { Standardized Coefficients } \\
\text { Beta }\end{array}$} & \multirow[t]{2}{*}{ t-test } & \multirow[t]{2}{*}{ p-Value } & \multicolumn{3}{|c|}{ Correlations } \\
\hline & Beta & Standard error & & & & Zero-order & Partial & Part \\
\hline (Constant) & 12.151 & 0.717 & & 16.943 & 0.000 & & & \\
\hline Stress & -0.142 & 0.047 & 0.147 & 3.003 & 0.003 & 0.147 & 0.147 & 0.147 \\
\hline \multicolumn{9}{|c|}{ Dependent Variable: self-efficacy } \\
\hline \multicolumn{9}{|c|}{ Bolded are statistically significant $p$-Values $(<0.05)$} \\
\hline
\end{tabular}


Table 5

Backward elimination multiple linear regression.

\begin{tabular}{|c|c|c|c|c|c|c|c|c|}
\hline \multirow[t]{2}{*}{ Model } & \multicolumn{2}{|c|}{ Unstandardized Coefficients } & \multirow{2}{*}{$\begin{array}{l}\text { Standardized Coefficients } \\
\text { Beta }\end{array}$} & \multirow[t]{2}{*}{ t-test } & \multirow[t]{2}{*}{ p-Values } & \multicolumn{3}{|c|}{ Correlations } \\
\hline & Beta & Std. Error & & & & Zero-order & Partial & Part \\
\hline (Constant) & 17.893 & 3.067 & & 5.835 & 0.000 & & & \\
\hline Emotional exhaustion & -0.016 & 0.008 & -0.105 & -2.147 & 0.032 & -0.102 & -0.106 & -0.104 \\
\hline Depersonalization & 0.026 & 0.014 & 0.089 & 1.827 & 0.068 & 0.084 & 0.091 & 0.089 \\
\hline Anxiety & -0.293 & 0.153 & -0.094 & -1.913 & 0.056 & -0.087 & -0.095 & -0.093 \\
\hline Stress & -0.135 & 0.047 & 0.140 & 2.879 & 0.004 & 0.147 & 0.142 & 0.140 \\
\hline \multicolumn{9}{|c|}{ Dependent Variable: Self-efficacy } \\
\hline \multicolumn{9}{|c|}{ Bolded are statistically significant $p$-Values $(<0.05)$} \\
\hline
\end{tabular}

\section{Discussions}

The COVID-19 outbreak in China overwhelmed healthcare facilities in the epicenter, Wuhan, causing the drafting of healthcare workers from the countryside to Wuhan. Our study evaluated the effect of burnout, depression, anxiety, and stress on general self-efficacy of drafted nurses returning from Wuhan.

A total of 408 (Mean age: $36.67 \pm 11.21$ ) nurses had returned to our hospital from Wuhan. All drafted nurses (100\%) participated in our study. All 408(100\%) were females, of whom 279 (68.4\%) were single. The majority $192(47.1 \%)$ of our participants had a technical secondary school diploma. From our results, the majority of nurses demonstrated high levels of burnout with depersonalization (73.1\%), emotional exhaustion (57.8\%), and reduced levels of personal achievements (59.1\%). These results coincide with those by (22), who not only demonstrated higher burnout levels among healthcare workers in Wuhan as compared to other areas, but also the burden of burnout decreasing with increasing distance from Wuhan. Our findings, however, contradict with Wu et al. (2020)(23) who reported lower levels of burnout with less than 13\% of front line healthcare workers in Wuhan having higher levels of emotional exhaustion or depersonalization; and 39\% have reduced levels of personal achievement. In contrast to our study whereby participants came from an area with a lower burden of infection, Wu et al. (2020) utilized participants permanently employed to Wuhan health facilities. The differences in the psychological adjustments to the Wuhan setting among participants could explain the differences in burnout levels between the two studies.

The majority of participants had extremely high levels of depression (88.48\%), anxiety (100\%), and stress (99.76\%). From a previous study by Lee et al. (2018)(24), levels of depression and anxiety were reported to be $11 \%$ and $15.1 \%$, respectively, among nurses during the MERS outbreak about a decade ago. In another study, Chen et al. (2006)(25) assessed nurses caring for SARS patients during the 2002 outbreak and found a $31.9 \%$ level of stress among them. Ko et al. (2006)(26) reported 3.7\% depression level among healthcare workers during the SARS outbreak in Taiwan, while Wu et al. (2008)(27) reported $77.2 \%$ in Beijing with associated alcohol abuse and dependence. The reason for the differences could be due to higher infection rates demonstrated by COVID-19 but also the role of widespread internet usage of social media, which at times spread rumors inducing anxiety and panic to the public.

Regarding self-efficacy, our study reported that all participants (100\%) had levels that were below average (i.e., $14.28 \pm 2.12)$. This is in contrast to the result by Ratnayake et al. (2016)(28) during the Ebola virus disease (EVD) outbreak where general self-efficacy among nurses caring for the sick was above average defined by median of 4 (i.e., strongly agree) in the general self-efficacy Likert scale. In another study by Ko et al. (2004)(29), the mean general self-efficacy among nurses caring for SARS patients in Taiwan was $11.38 \pm 12.98$, which is lower than the one reported from our results. The study by Ratnayake et al. was conducted 2 years after the official announcement of the EVD outbreak in Sierra-Leone. After the epidemic had passed its peak, healthcare workers had already developed psychological acceptance, and they had already received thorough safety training courses, adequate medical supplies, and personal protective equipment (PPE) from WHO and partners. This is in contrast to our study, which was conducted about 2 months after the official announcement of the outbreak when the knowledge and experience of the disease were limited, the public was in a panic, the outbreak had not yet reached its peak, and PPE was inadequate. Time differences in conducting the studies could explain the differences in the self-efficacy results reported. We call upon for studies comparing trends of self-efficacies during different time points in the infection curve.

From our study, emotional exhaustion (Beta $=-0.016, p-V a l u e=0.034)$ and stress (Beta $=-0.138, p-V a l u e=0.004)$ were found to negatively affect general self-efficacy significantly. Anxiety, personal achievement, depersonalization, and depression did not show a statistically significant relationship with general self-efficacy. The results for anxiety contradict those reported by Ho et al. (2005)(30). They reported that increased anxiety significantly lowered self-efficacy among nurses during the SARS outbreak in 2002. In another study by $\mathrm{Ng}$ et al. (2006)(31) demonstrated that lower levels of depression among nurses caring for SARS patients were significantly associated with increased general-self efficacy. SARS had about 4 times higher fatality rate as compared to COVID-19 (32). This could mean that SARS created higher anxiety and depression levels in healthcare works as compared 
to COVID-19. We unexpectedly found a small positive correlation between depersonalization and general self-efficacy. Authors believe this was due to the encountered biases in our study. We call upon for lesser biased studies such as systematic reviews and meta-analyses on the topic.

In an attempt to stall the spread of COVID-19 amid the world's effort to develop new treatments and manufacture dire needed medical equipment, WHO officials during the World Economic Forum's briefing, recommended countries to practice "Isolate, Test, Treat and Trace." We support the slogan. However, we believe that the slogan is disproportionately favoring patients than healthcare workers. We, therefore, recommend to healthcare systems and partners to provide psychological support, protective training, and adequate PPE to healthcare workers. We also promote paying tributes to healthcare workers and other public service front liners across the world through cheering and encouragement posts in social media.

\section{Limitations and strengths of the study}

Despite promising results, authors urge readers to interpret these results with caution due to several encountered biases. To mitigate non-response biases, adequate time (i.e., 1 week) to respond was given, confidentiality was guaranteed, and electronically accessed questionnaires were previously tested for compatibility to different electronic devices. Correspondence with participants was made possible through a joint WeChat group; therefore, mitigating attrition biases. The STROBE tool was utilized in the write-up to alleviate reporting and publication biases.

On the other hand, the extensive popular and nearly a "must-have" mobile application in China, WeChat, made it possible to reach all participants effectively. This reliable platform for correspondence may explain our study's strength achieving a 100\% participants' response rate. Moreover, the participants had received a "hero-welcoming" upon their return from Wuhan. From an otherwise a weaker basis, such welcoming might also have motivated the participants to take part in the interviews.

\section{Conclusion}

COVID-19 disease outbreak in China, overwhelmed healthcare facilities creating burnout, anxiety, stress, and depression among nurses working in the hard-hit areas. These may explain an observed lower than average general self-efficacy. However, only stress and emotional exhaustion were associated with reduced general self-efficacy among nurses. Decreased nurses' general self-efficacy may increase medical errors, thus reducing patients' safety. We, therefore, recommend healthcare systems and partners to provide more support to healthcare workers in terms of psychological support, provision of protective training, and supply of adequate PPE. We also promote paying tributes to healthcare workers and other public service front liners across the world through cheering and encouragement posts in social media.

\section{List Of Abbreviations}

COVID-19 - Coronavirus Disease 2019

2019-nCOV - 2019 Novel Corona Virus

SARS-CoV-2 - Severe Acute Respiratory Syndrome Coronavirus 2

MBI - Maslach Burnout Inventory,

GSES - General Self-Efficacy Scale

DASS - Depression Anxiety Stress Scales

IRB - Institution's Review Board

EVD - Ebola Virus Disease

WHO - World Health Organization

\section{Declarations}

Ethics approval and consent to participate: Written consent and IRB approval were obtained.

Consent for publication: Written consent was obtained.

Availability of data and materials: All data generated or analyzed during this study are included in this published article [and its supplementary information files].

Competing interests: Authors declared no competing interests

Funding: No funds were given 
Author's contributions: Study designing: YK and JZ; data collection YK and JS; data analysis and interpretation: JS; Manuscript drafting: JS; manuscript critical intellectual content revision: YK, JS, and JZ. All authors read and approved the final version of the manuscript.

Acknowledgements: Not applicable

\section{References}

1. Kaplan EH. Containing 2019-nCoV (Wuhan) coronavirus. Health care management science. 2020.

2. Conway MJ. Identification of Coronavirus Sequences in Carp cDNA from Wuhan, China. Journal of medical virology. 2020.

3. Lake MA. What we know so far: COVID-19 current clinical knowledge and research. Clinical medicine (London, England). 2020.

4. Peng X, Xu X, Li Y, Cheng L, Zhou X, Ren B. Transmission routes of 2019-nCoV and controls in dental practice. Int J Oral Sci. 2020;12(1):9.

5. Rothan HA, Byrareddy SN. The epidemiology and pathogenesis of coronavirus disease (COVID-19) outbreak. Journal of autoimmunity. 2020:102433.

6. Zhai P, Ding Y, Wu X, Long J, Zhong Y, Li Y. The epidemiology, diagnosis and treatment of COVID-19. Int J Antimicrob Agents. 2020:105955-.

7. Maffioli EM. How Is the World Responding to the 2019 Coronavirus Disease Compared with the 2014 West African Ebola Epidemic? The Importance of China as a Player in the Global Economy. The American journal of tropical medicine and hygiene. 2020.

8. Lin Q, Zhao S, Gao D, Lou Y, Yang S, Musa SS, et al. A conceptual model for the outbreak of Coronavirus disease 2019 (COVID-19) in Wuhan, China with individual reaction and governmental action. International journal of infectious diseases: IJID : official publication of the International Society for Infectious Diseases. 2020.

9. The World Health Organization; 2020. Available from: https://www.who.int/emergencies/diseases/novel-coronavirus-2019/events-as-theyhappen. Accessed March 15, 2020.

10. Cascella M, Rajnik M, Cuomo A, Dulebohn SC, Di Napoli R, Features. Evaluation and Treatment Coronavirus (COVID-19). StatPearls. Treasure Island (FL): StatPearls Publishing.

11. StatPearls Publishing LLC.; 2020.

12. Gong F, Xiong Y, Xiao J, Lin L, Liu X, Wang D, et al. China's local governments are combating COVID-19 with unprecedented responses - from a Wenzhou governance perspective. Frontiers of medicine. 2020.

13. Hollander JE, Carr BG. Virtually Perfect? Telemedicine for Covid-19. The New England journal of medicine. 2020.

14. Montag C, Becker B, Gan C. The Multipurpose Application WeChat: A Review on Recent Research. Front Psychol. 2018;9:2247-.

15. Maslach C, Jackson S. Maslach Burnout Inventory - Human Services Survey (HSS)1996.

16. Yao Y, Yao W, Wang W, Li H, Lan Y. Investigation of risk factors of psychological acceptance and burnout syndrome among nurses in China. Int $J$ Nurs Pract. 2013;19(5):530-8.

17. Poghosyan L, Aiken LH, Sloane DM. Factor structure of the Maslach burnout inventory: an analysis of data from large scale cross-sectional surveys of nurses from eight countries. International journal of nursing studies. 2009;46(7):894-902.

18. Chen G, Gully S, Eden D. Validation of a New General Self-Efficacy Scale. Organizational Research Methods - ORGAN RES METHODS. $2001 ; 4$.

19. Cheung SK, Sun SY. Assessment of optimistic self-beliefs: further validation of the Chinese version of the General Self-Efficacy Scale. Psychological reports. 1999;85(3 Pt 2):1221-4.

20. Chan R, Xu T, Huang J, Wang Y, Zhao Q, Shum D, et al. Extending the utility of the Depression Anxiety Stress scale by examining its psychometric properties in Chinese settings. Psychiatry research. 2012;200.

21. Wang K, Shi HS, Geng FL, Zou LQ, Tan SP, Wang Y, et al. Cross-cultural validation of the Depression Anxiety Stress Scale-21 in China. Psychol Assess. 2016;28(5):e88-100.

22. Heinen MM, van Achterberg T, Schwendimann R, Zander B, Matthews A, Kozka M, et al. Nurses' intention to leave their profession: a cross sectional observational study in 10 European countries. International journal of nursing studies. 2013;50(2):174-84.

23. Zhang SX, Huang H, Wei F. Geographical distance to the epicenter of Covid-19 predicts the burnout of the working population: Ripple effect or typhoon eye effect? Psychiatry Res. 2020;288:112998.

24. Wu Y, Wang J, Luo C, Hu S, Lin X, Anderson AE, et al. A comparison of burnout frequency among oncology physicians and nurses working on the front lines and usual wards during the COVID-19 epidemic in Wuhan, China. Journal of pain and symptom management. 2020.

25. Lee SM, Kang WS, Cho AR, Kim T, Park JK. Psychological impact of the 2015 MERS outbreak on hospital workers and quarantined hemodialysis patients. Compr Psychiatr. 2018;87:123-7.

26. Chen R, Chou KR, Huang YJ, Wang TS, Liu SY, Ho LY. Effects of a SARS prevention programme in Taiwan on nursing staff's anxiety, depression and sleep quality: a longitudinal survey. International journal of nursing studies. 2006;43(2):215-25.

27. Ko CH, Yen CF, Yen JY, Yang MJ. Psychosocial impact among the public of the severe acute respiratory syndrome epidemic in Taiwan. J Neuropsychiatry Clin Neurosci. 2006;60(4):397-403. 
28. Wu P, Liu X, Fang Y, Fan B, Fuller CJ, Guan Z, et al. Alcohol abuse/dependence symptoms among hospital employees exposed to a SARS outbreak. Alcohol Alcohol. 2008;43(6):706-12.

29. Ratnayake R, Ho LS, Ansumana R, Brown H, Borchert M, Miller L, et al. Improving Ebola infection prevention and control in primary healthcare facilities in Sierra Leone: a single-group pretest post-test, mixed-methods study. BMJ Glob Health. 2016;1(4):e000103-e.

30. Ko NY, Feng MC, Chiu DY, Wu MH, Feng JY, Pan SM. Applying theory of planned behavior to predict nurses' intention and volunteering to care for SARS patients in southern Taiwan. Kaohsiung J Med Sci. 2004;20(8):389-98.

31. Ho SM, Kwong-Lo RS, Mak CW, Wong JS. Fear of severe acute respiratory syndrome (SARS) among health care workers. J Consult Clin Psychol. 2005;73(2):344-9.

32. Ng SM, Chan TH, Chan CL, Lee AM, Yau JK, Chan CH, et al. Group debriefing for people with chronic diseases during the SARS pandemic: Strength-Focused and Meaning-Oriented Approach for Resilience and Transformation (SMART). Commun Ment Health J. 2006;42(1):53-63.

33. Petrosillo N, Viceconte G, Ergonul O, Ippolito G, Petersen E. COVID-19, SARS and MERS: are they closely related? Clinical microbiology and infection: the official publication of the European Society of Clinical Microbiology and Infectious Diseases. 2020.

\section{Figures}

\section{Normal P-P Plot of Regression Standardized Residual}

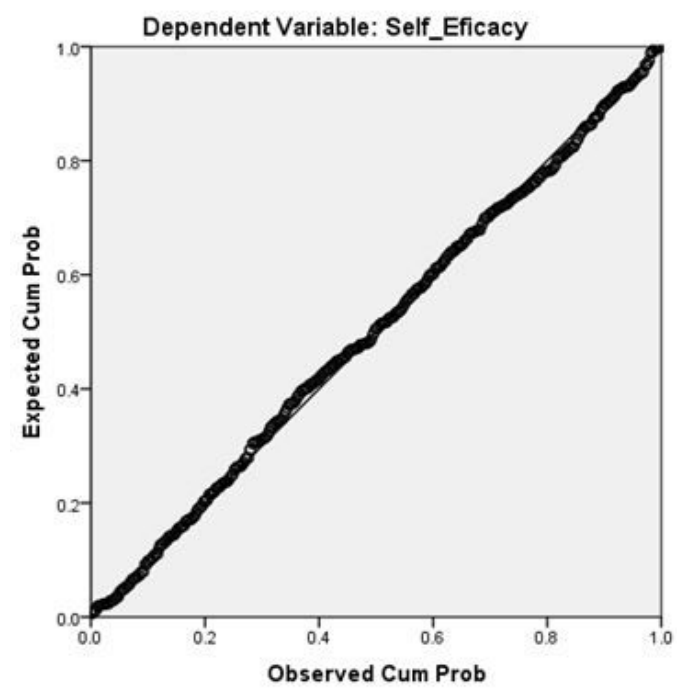

Figure 1

Normal Probability-Probability plot of regression standardized residual

Scatterplot

Dependent Variable: Self_Eficacy

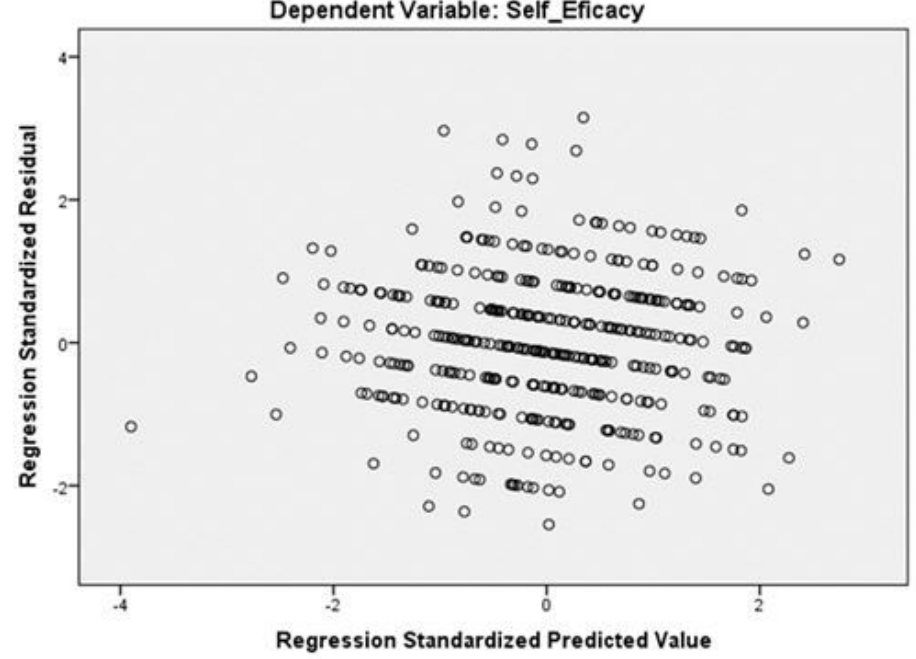

Figure 2 
Scatterplot for standardized residual and standardized predicted value.

\section{Supplementary Files}

This is a list of supplementary files associated with this preprint. Click to download.

- RawData.xlsx

- SupplemenatryFile1.doc 